\title{
Expression profiling of the ubiquitin conjugating enzyme UbcM2 in murine brain reveals modest age-dependent decreases in specific neurons
}

\author{
Chelsea M. Larabee ${ }^{1,3}$, Constantin Georgescu², Jonathan D. Wren ${ }^{2}$ and Scott M. Plafker ${ }^{1,3^{*}}$
}

\begin{abstract}
Background: UbcM2 is a ubiquitin-conjugating enzyme with roles in the turnover of damaged and misfolded proteins, cell cycle progression, development, and regulation of the antioxidant transcription factor, Nrf2. Recent screens have identified binding partners of the enzyme that are associated with various neurodegenerative diseases, and our previous studies have shown that $\mathrm{UbcM} 2$ is enriched in retina and brain.

Results: In the current study, we characterized UbcM2 protein expression in various structures and cell types in the murine brain. Immunofluorescence analysis of paraffin-embedded brain sections revealed that UbcM2 is ubiquitously expressed throughout the brain, is enriched in hindbrain and cortex, and is robustly expressed in neurons. In contrast, the enzyme is undetectable in most astrocytes and microglia. As dysfunction of the ubiquitin proteasome system (UPS) has been linked to many age-related neurological diseases, we compared UbcM2 expression levels in young versus aged wild-type mice and found a global decrease in expression in aged brains, with reductions of $10 \%$ or greater in five substructures (cerebellar granule cell layer, primary motor cortex, olfactory nucleus, superior colliculus, and secondary visual cortex).

Conclusions: These studies represent the first protein expression profiling of a ubiquitin-conjugating enzyme in the brain and support the notion that deficits in protein degradation and proteostasis associated with neurodegenerative diseases may be, in part, attributable to age-dependent reductions in the enzymatic machinery of the UPS.
\end{abstract}

Keywords: Ubiquitin, UbcM2, Neurons, Hindbrain, Cortex

\section{Background}

The ubiquitin $(\mathrm{Ub})$ proteasome system (UPS) is a major intracellular protein degradation pathway. The central protein of this pathway is $\mathrm{Ub}$, a highly conserved 76 amino acid polypeptide that is conjugated to target proteins through a hierarchal enzyme cascade consisting of a Ub-activating enzyme (E1), a Ub-conjugating enzyme (E2), and a Ub ligase (E3). E3s can be single proteins or multi-subunit complexes that recruit and facilitate the transfer of Ub to substrates. Humans have at least two E1s, 36-40 E2s, and

\footnotetext{
*Correspondence: plafkers@omrf.org

${ }^{1}$ Aging and Metabolism Research Program, Oklahoma Medical Research

Foundation, 825 Northeast 13th Street, Oklahoma City, OK, USA

Full list of author information is available at the end of the article
}

up to 1000 E3s [1]. Thus, a single E2 can partner with a host of E3s, and, likewise, a given E3 can engage multiple E2s. Ubiquitylation targets recipient proteins to a number of fates, the best studied of which is degradation by the $26 \mathrm{~S}$ proteasome. Ubiquitylation has also been shown to regulate protein localization, DNA repair, signal transduction, and a host of other functions (reviewed in [2]). A distinct class of enzymes collectively referred to as de-ubiquitylating enzymes, or DUBs, counter ubiquitylation by removing Ub from substrates. The balance between ubiquitylation and de-ubiquitylation must therefore be finely tuned to maintain proteostasis and cellular fidelity.

Dysregulation of the UPS is associated with many pathologies, including cardiovascular, inflammatory, and 
neurodegenerative diseases. UPS activity decreases in normal aging as well as in Alzheimer's disease [3], Parkinson's disease [4], and age-related macular degeneration $[5,6]$. Consequently, a cardinal hallmark of these diseases is the accumulation of toxic protein aggregates; these are often associated with oxidative and proteotoxic stress and damage [7]. In most disorders, it remains to be determined if decreased UPS activity is a primary cause or a secondary consequence of these neurodegenerative pathologies.

A great deal of work has been done to characterize the biochemical mechanisms employed by E2s and E3s, but few studies have focused on cataloging the expression profiles of these enzymes in different organs, tissues, and cell types. In the work reported here, we analyzed the protein expression profile of UbcM2 in the brain. This enzyme is a highly-conserved metazoan E2 that plays roles in proteasome-mediated turnover of proteins [8], cell cycle progression $[9,10]$, and regulation of the antioxidant transcription factor, Nrf2 [11, 12]. The human and mouse protein sequences of UbcM2 are identical, and the human form is called UBE2E3. Although a comprehensive assessment of the in vivo functions of UbcM2 has not been performed in higher organisms, a functional homolog in yeast has been shown to mediate the degradation of misfolded and oxidatively-damaged proteins [8]. We have previously shown that the enzyme is ubiquitously expressed throughout the body but is enriched in the retina and brain in mice [13]. We further characterized the expression profile in the neuroretina as well as the retinal pigment epithelium [13]. Subsequently, high throughput screens for protein-protein interactions revealed that UbcM2 interacts with the Huntington's Disease proteins HTT [14] and RNF2 [15] and with the spinocerebellar ataxia-associated protein ATXN1 [16]. More recently, UbcM2 was shown to play a major role in the ubiquitylation status of TDP-43, a DNA-binding protein found in aggregates of amyotrophic lateral sclerosis and subtypes of frontotemporal lobar degeneration [17]. These interactions prompted us to carry out a cell typeand structure-specific immunofluorescence analysis of UbcM2 in mouse brain tissue and to determine if expression of the enzyme is altered in aged mice. We report here the first assessment of the localization and abundance of an E2 in the brain. This study serves as a launching point for the characterization of E2s in both healthy and pathological brains with the hopes of better understanding how UPS deficits contribute to neuropathologies.

\section{Results}

\section{Validation of the a-UbcM2 antibody}

To determine the protein expression profile of UbcM2 in mouse brain, a rabbit polyclonal antibody raised against the $\mathrm{N}$-terminal 58 residues of UbcM2 was affinity purified and validated in HeLa cells treated with either control siRNA (siCON) or UbcM2-specific siRNA (siUbcM2). 3 days post-siRNA treatment, cells were fixed and immunostained with $\alpha$-UbcM2 and nuclei were counterstained with DAPI. $\alpha$-UbcM2 labeling revealed that the enzyme localized to the nucleus (Fig. 1A, panel c), as we reported previously $[18,19]$, and that the knockdown efficiency was 60-70 \% (data not shown). Western blot analysis from human retinal pigment epithelial cellderived lysates treated with siCON or siUbcM2 shows a single band at the size of UbcM2 $(23 \mathrm{kDa})$ in siCONtreated cells and loss of the band in siUbcM2-treated cells (Fig. 1B). Additional validation of $\alpha$-UbcM2 came from analyzing mouse embryo fibroblasts (MEFs) harboring floxed alleles of UbcM2 and stably transduced with trimethoprim-inducible Cre recombinase. As shown in Fig. 1C, Cre was induced in three of the four cells in the field and led to ablation of the $\alpha$-UbcM2 signal in all three cells. The cell lacking Cre expression retained UbcM2 immunolabeling. In cell lysates derived from mouse cerebellum (CB) and cortex (Ctx), $\alpha$-UbcM2 detected a single band of the predicted migration for the enzyme (Fig. 1D).

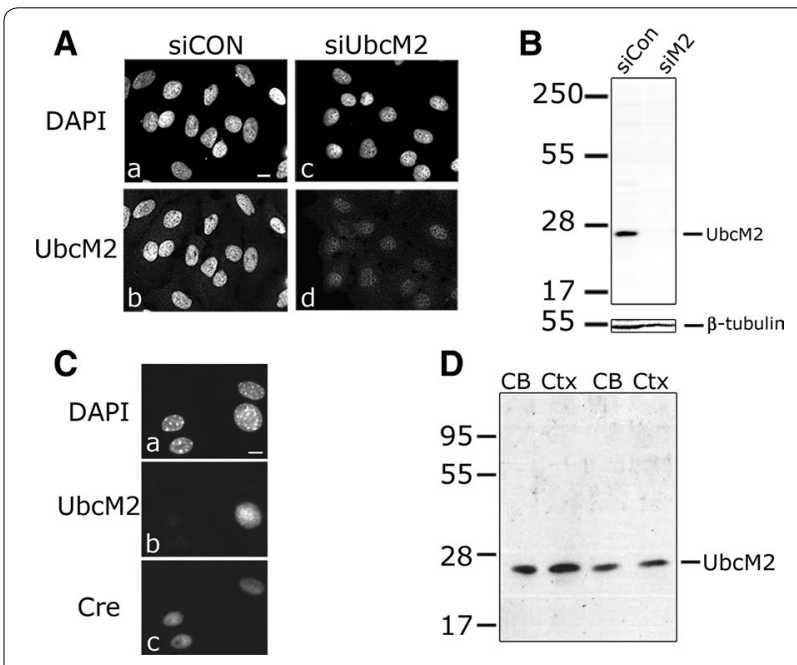

Fig. 1 Validation of a-UbcM2 antibody. A HeLa cells were treated with 12 pmol of control siCON siRNA $(a, b)$ or UbcM2-specific siRNA $(c, d)$ for $72 \mathrm{~h}$ before fixation and immunostaining with a-UbcM2 ( $b$, d). Nuclei were counterstained with DAPI $(a, c) .60 \times$, size bar $10 \mu \mathrm{m}$. B RPE-1 cells were treated with siCON (left lane) or siUbcM2 (right lane) for $72 \mathrm{~h}$ and solubilized for western blot analysis with a-UbcM2. Anti- $\beta$-tubulin is used as a loading control. C UbcM2 $2^{\text {Flox/Flox } M E F s ~}$ expressing an inducible Cre recombinase were fixed and labeled with DAPI (a), a-UbcM2 (b), and a-Cre (c). 3 of the 4 cells express Cre and lose UbcM2 expression whereas the non-Cre expressing cell retains UbcM2 expression. D Cell lysates prepared from mouse cerebellum (CB) and cortex (Ctx) were analyzed by a-UbcM2 western blot analysis 


\section{UbcM2 is expressed in neurons and oligodendrocytes of mouse brain}

We next co-immunolabeled sagittal brain sections with $\alpha$-UbcM2 and antibodies specific for various cell types resident in brain. Co-staining with an antibody against the nuclear neuronal marker $\mathrm{NeuN}$ revealed that the overwhelming majority of UbcM2 is expressed in neurons and that essentially all neurons express the enzyme (Fig. 2A). UbcM2 expression was also consistently observed in CNPase-positive oligodendrocytes throughout brain (Fig. 2B). Within the limits of detection of the UbcM2 antibody, the enzyme was minimally detected or absent in most microglia, labeled by $\alpha$-Iba1 staining (Fig. 2C), and in astrocytes, labeled by $\alpha$-GFAP staining (Fig. 2D). Curiously, a subpopulation of microglia and astrocytes displayed robust UbcM2 expression, examples of which are depicted in representative images of hippocampal CA1 sections (white arrows in Fig. 2C, panel d, and Fig. 2D, panel d, respectively). What distinguishes these rare cells from the remainder of glial cells that do not express detectable levels of UbcM2 remains to be determined. Due to the prevalence of UbcM2 in NeuN-positive cells (i.e., neurons), we focused the remainder of this study on quantitatively analyzing the relative expression levels of UbcM2 in neurons.

\section{UbcM2 is universally expressed in neurons} throughout mouse brain

Sagittal brain sections were probed with $\alpha$-UbcM2 and $\alpha-\mathrm{NeuN}$ to determine the relative expression of neuronal UbcM2 in 22 anatomically-distinct structures. A mouse brain atlas [20] was used during the sectioning and analysis to ensure correct orientation using white matter, cerebellum, and various structural markers as landmarks. These landmarks also ensured that studies compared the same sagittal plane(s) within each brain. Representative photomicrographs of UbcM2 staining in various substructures (Fig. 3A) demonstrate the range observed throughout the brain, with relatively high expression detected in pontine nuclei (Fig. 3A, panel c), intermediate levels detected in hippocampal CA1 and cingulate cortex (Fig. 3A, panels g and k, respectively), and relatively low levels observed in caudate putamen (Fig. 3A, panel o). Notably, UbcM2 was detected in all substructures

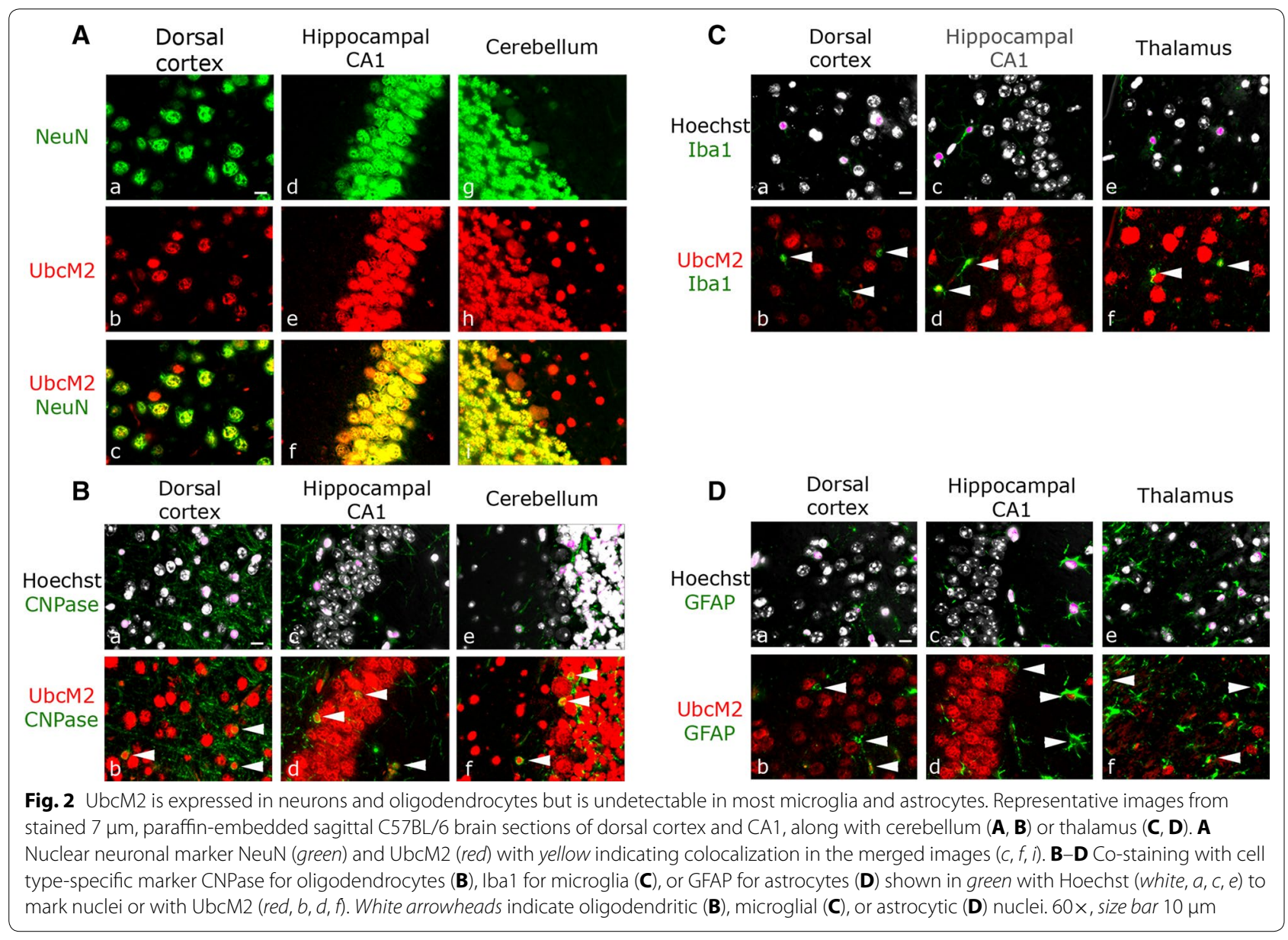




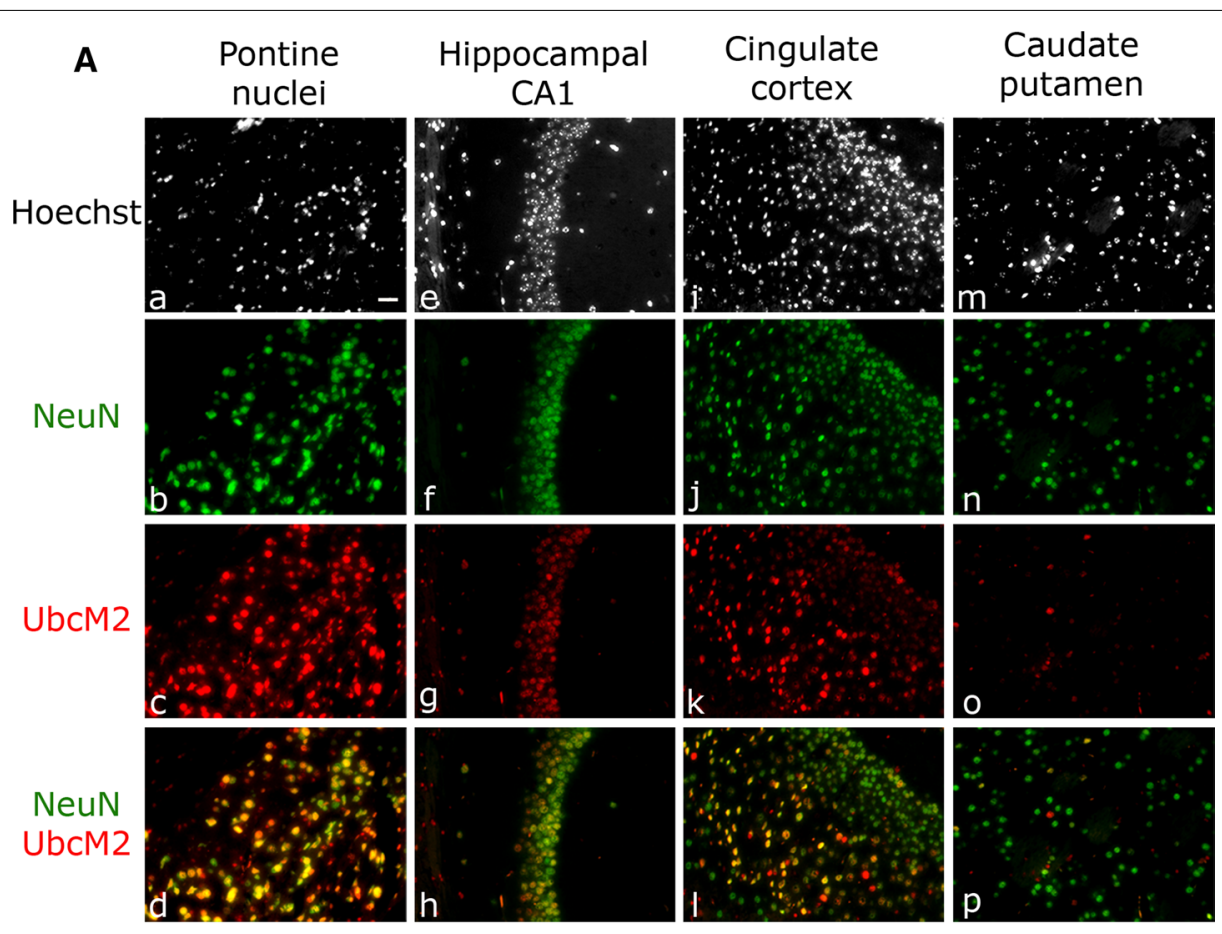

B

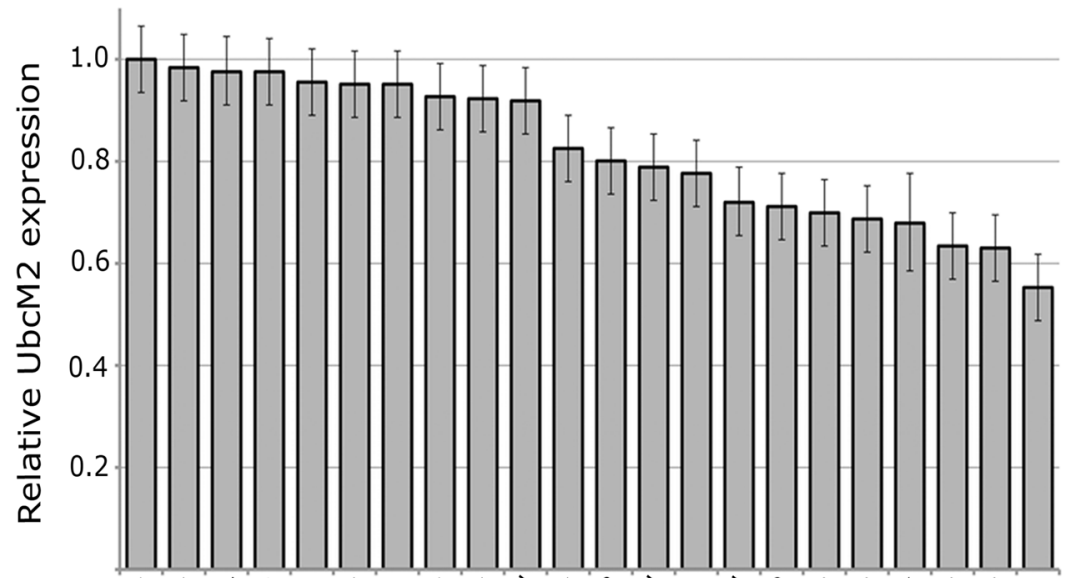

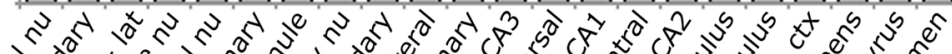

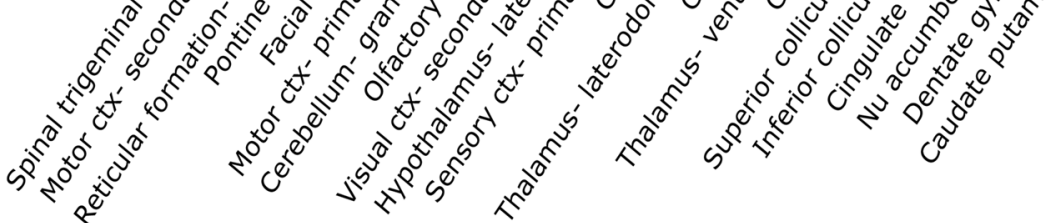

Fig. 3 Neurons express UbcM2 at relatively high levels in hindbrain and low levels in caudate putamen. A Representative images of $7 \mu$ m, paraffinembedded sagittal brain sections from a 4-month old C57BL/6 mouse. Anatomical regions shown are pontine nuclei ( $a-d)$, hippocampal CA1 (e-h), cingulate cortex $(i-l)$, and caudate putamen $(m-p)$. DNA is counterstained with Hoechst (white), and sections are immunostained for the nuclear neuronal marker NeuN (green) and UbcM2 (red). Co-localization of NeuN and UbcM2 is indicated by yellow in the merged images ( $d$, $h$, I, $p)$. $20 \times$, size bar $30 \mu \mathrm{m}$. B Brain substructure-specific UbcM2 expression as measured by fluorescence intensity relative to the area of highest expression (spinal trigeminal nucleus). Error bars indicate $95 \%$ confidence intervals. Disjoint confidence interval bars identify regions with significantly different UbcM 2 levels

surveyed [Fig. 3B; Table 1 ("relative UbcM2 expression" column), and Additional file 1: Figure S1]. Relatively high expression was detected in hindbrain and many cortical areas, whereas hippocampus and several basal ganglia components exhibited lower expression of the enzyme (Fig. 3B, Additional file 1: Figure S1). 
Table 1 UbcM2 expression is decreased in the neurons of specific substructures of the mouse brain

\begin{tabular}{|c|c|c|c|}
\hline Brain structure & $\begin{array}{l}\text { Relative UbcM2 } \\
\text { expression }\end{array}$ & $\begin{array}{l}\text { UbcM2 expression } \\
\% \text { change in aged } \\
\text { mice }\end{array}$ & P value \\
\hline CA1 & 0.776 & -11.518 & 0.0590 \\
\hline CA2 & 0.711 & -9.714 & 0.1500 \\
\hline CA3 & 0.801 & -7.614 & 0.1800 \\
\hline Caudate putamen & 0.553 & -6.471 & 0.4500 \\
\hline $\begin{array}{l}\text { Cerebellum-granule } \\
\text { layer }\end{array}$ & 0.951 & -14.530 & 0.0032 \\
\hline Cingulate ctx & 0.679 & 1.317 & 0.8900 \\
\hline Dentate gyrus & 0.630 & 1.806 & 0.8100 \\
\hline Facial nu & 0.955 & 1.957 & 0.6900 \\
\hline $\begin{array}{l}\text { Hypothalamus- } \\
\text { lateral }\end{array}$ & 0.919 & 6.637 & 0.1800 \\
\hline Inferior colliculus & 0.687 & -7.692 & 0.2800 \\
\hline Motor ctx-primary & 0.951 & -11.111 & 0.0260 \\
\hline Motor ctx-secondary & 0.984 & -5.372 & 0.2600 \\
\hline Nucleus accumbens & 0.634 & -7.051 & 0.3500 \\
\hline Olfactory nu & 0.927 & -10.526 & 0.0410 \\
\hline Pontine nu & 0.976 & 7.083 & 0.1400 \\
\hline $\begin{array}{l}\text { Reticular formation- } \\
\text { lateral }\end{array}$ & 0.976 & -0.917 & 0.8500 \\
\hline Sensory ctx-primary & 0.825 & -10.837 & 0.0560 \\
\hline Spinal trigeminal nu & 1.000 & -8.943 & 0.0600 \\
\hline Superior colliculus & 0.699 & -14.535 & 0.0320 \\
\hline $\begin{array}{l}\text { Thalamus-latero- } \\
\text { dorsal }\end{array}$ & 0.789 & -3.247 & 0.5800 \\
\hline Thalamus-ventral & 0.720 & -0.847 & 0.9000 \\
\hline Visual ctx-secondary & 0.923 & -11.454 & 0.0290 \\
\hline
\end{tabular}

The expression levels of $\mathrm{UbcM} 2$ in the brains of young and aged mice were measured and compared by average cellular a-UbcM2-derived fluorescence intensity in NeuN-positive nuclei. A $5.5 \%$ global decrease of UbcM2 expression was detected in aged versus their strain-matched, younger counterparts. The italic numbers indicate decreases of UbcM2 expression of $10 \%$ or greater in particular substructures of the brain

\section{UbcM2 expression is modestly decreased in aged mouse brain}

As the function and efficiency of the UPS decline with age (reviewed in [21, 22]), we next compared the expression levels of UbcM2 in the brains of young and aged mice. Young mice were 1-4 months old, and aged mice ranged from 10-25 months. Sagittal brain sections were examined for neuronal UbcM2 expression as measured by average cellular $\alpha$-UbcM2-derived fluorescence intensity in NeuN-positive nuclei. An analysis consisting of 22 distinct substructures revealed a modest but statistically significant global decrease of UbcM2 expression of $5.5 \%$ ( $\mathrm{p}$ value $=0.046$ ) in aged animals as compared to their strain-matched, younger counterparts (Fig. 4A, B; Table 1). Five substructures in particular (cerebellar granule cell layer, primary motor cortex, olfactory nucleus, superior colliculus, and secondary visual cortex) exhibited statistically significant decreases of $10 \%$ or more as a function of age (Fig. 4A, C; Table 1, italic entries).

\section{UbcM2 expression is unchanged in aged Nrf2-deficient brains relative to aged wildtype}

We have shown that UbcM2 regulates Nrf2 [11, 12], an antioxidant transcription factor that induces the expression of genes encoding cytoprotective proteins and enzymes involved in redox homeostasis and proteostasis [23-25]. Thus, genetic ablation of Nrf2 is predicted to increase the abundance of oxidatively-damaged proteins destined for Ub-mediated degradation. Nonetheless, we did not observe altered levels or expression patterns of UbcM2 in aged cohorts of this knockout strain relative to age-and strain-matched controls (Fig. 5A; Table 2). Consistent with these data, we found by western blotting that the brains of these animals do not accumulate polyUb aggregates or heat shock protein 70 (HSP70), markers of disrupted proteostasis (Fig. 5B), or have increased antiUb labeling in paraffin sections (Fig. 5C). These data indicate that the steady-state level of overt proteotoxic stress in Nrf2 knockout brains is relatively minimal. Curiously, these knockout mice reportedly undergo spontaneous retinal degeneration in an age-dependent fashion [26]. We surmise that this phenotype is a function of the retina being exposed to the additional stress derived from constant photo-oxidative challenge throughout the life of the animal.

\section{Discussion}

The principal advance of this work is that it represents the first description of the cell- and structure-specific expression and distribution of a UPS E2 in the mouse brain. Our previous studies to develop a global UbcM2 knockout mouse strain resulted in a failure to produce homozygous knockouts, consistent with UbcM2 loss causing embryonic lethality (S. Plafker, unpublished results) and knockdown of the enzyme inducing a cell cycle arrest/exit [10]. The expression profiling described in the present study is therefore a requisite first step for directing future efforts at genetically ablating the enzyme in specific anatomical structures of the brain. Such knockouts could provide useful models to determine if and how UPS deficits contribute to neurodegeneration.

By immunological staining of paraffin-embedded murine brain sections with a highly specific antibody, we found that UbcM2 is ubiquitously expressed in neurons and oligodendrocytes but is undetectable in the majority of microglia and astrocytes (Fig. 2). These data largely reflect transcriptional profiling data for isolated astrocytes, neurons, and oligodendrocytes showing enrichment of the UbcM2 transcript (referred to by the human 


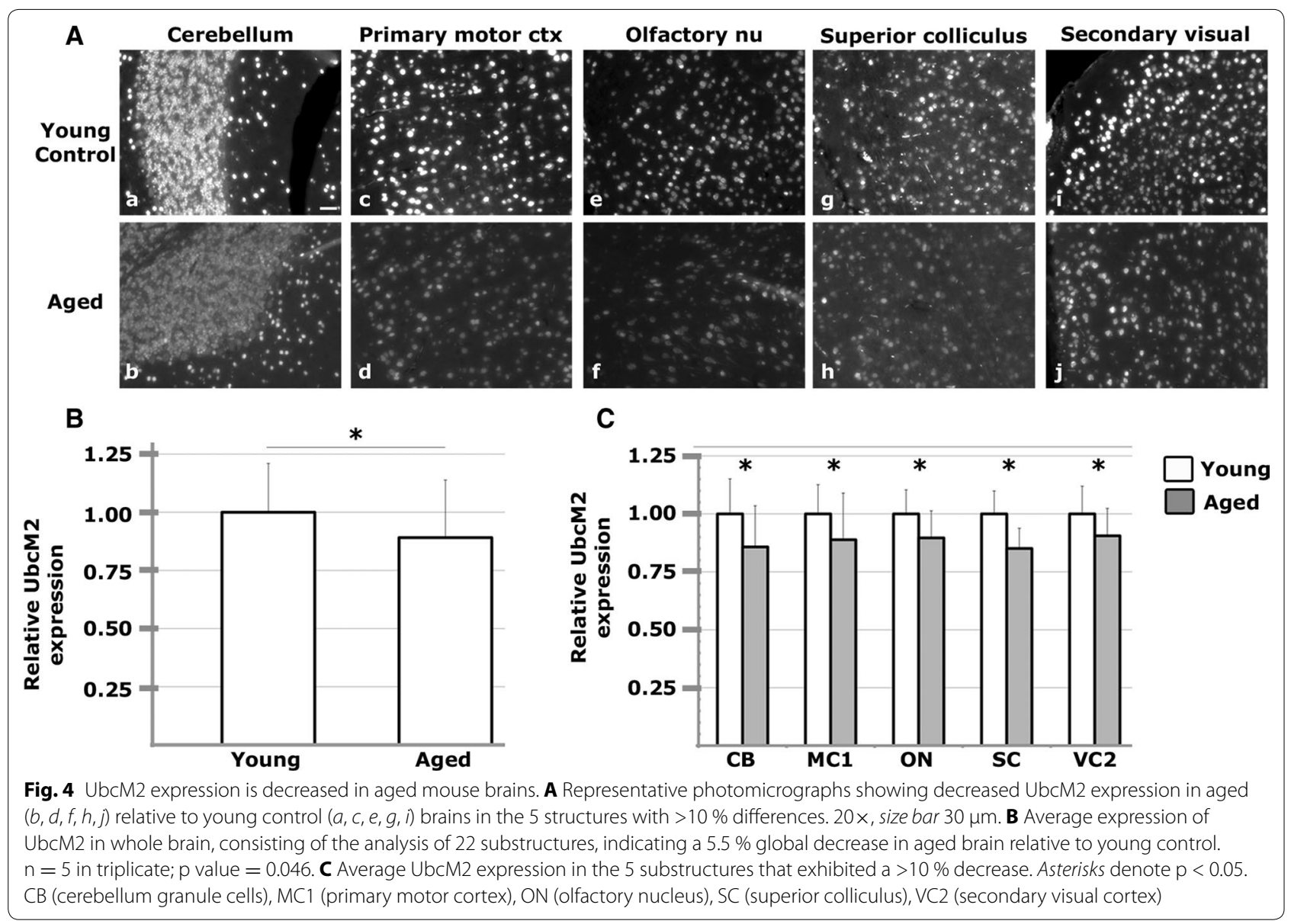

gene name, $U B E 2 E 3)$, as well as many other components of the UPS, in neurons and oligodendrocytes relative to astrocytes [27]. Approximately half the amount of UbcM2 mRNA was detected in astrocytes relative to neurons, and this level of astrocyte expression is likely due to the fact that the isolated cells were derived from very young mouse brains and cultured several days before analysis. UbcM2 is expressed in replicating cells and is necessary for cell replication [10]. Consistent with this, we hypothesize that the rare population of UbcM2-expressing astrocytes and microglia are likely replicating. Due to the prevalence of UbcM2 in neurons, we quantified the relative expression of the enzyme in NeuN-positive nuclei in 22 brain structures (Fig. 3, Additional file 1: Figure S1; Table 1). We observed relatively robust UbcM2 expression in hindbrain and cortical structures and lower expression in hippocampus and several basal ganglia components. As UPS dysfunction has been linked to multiple age-associated neuropathologies, we also examined whether UbcM2 expression levels change as a function of age. We observed a modest $5.5 \%$ global decrease in neuronal UbcM2 expression in aged brain with a more marked decrease (>10\%) in 5 substructures, namely cerebellar granule cell layer, primary motor cortex, olfactory nucleus, superior colliculus, and secondary visual cortex (Fig. 4; Table 1).

Our results are largely consistent with a qRT-PCR analysis of UbcM2 mRNA localization in mouse embryo [28]. Similar to our findings of protein expression in adult mice [13], UbcM2 mRNA was enriched in embryonic brain with lowest expression in heart and intermediate levels in lung, liver, and kidney. Within embryonic brain, high mRNA levels were detected in cortex and hindbrain, but unlike UbcM2 protein expression, the mRNA was also enriched in thalamus, midbrain, and hippocampus at various stages of embryonic development. These differences may be attributable to changes in UbcM2 expression during development versus post-development and/ or a discrepancy between protein and mRNA levels due to translational or degradative regulation.

Although genetic mutations of UbcM2 have not been linked to neurodegeneration to date, the enzyme is highly enriched in numerous brain areas devoted to motor output, including primary and secondary motor cortices, 


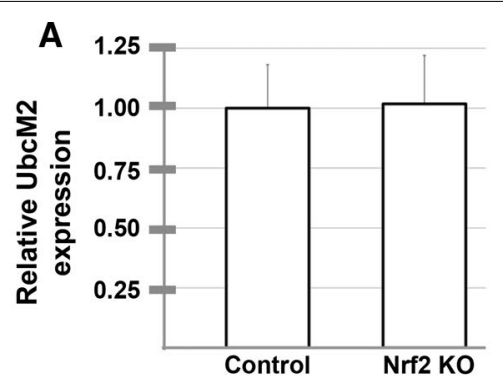

B
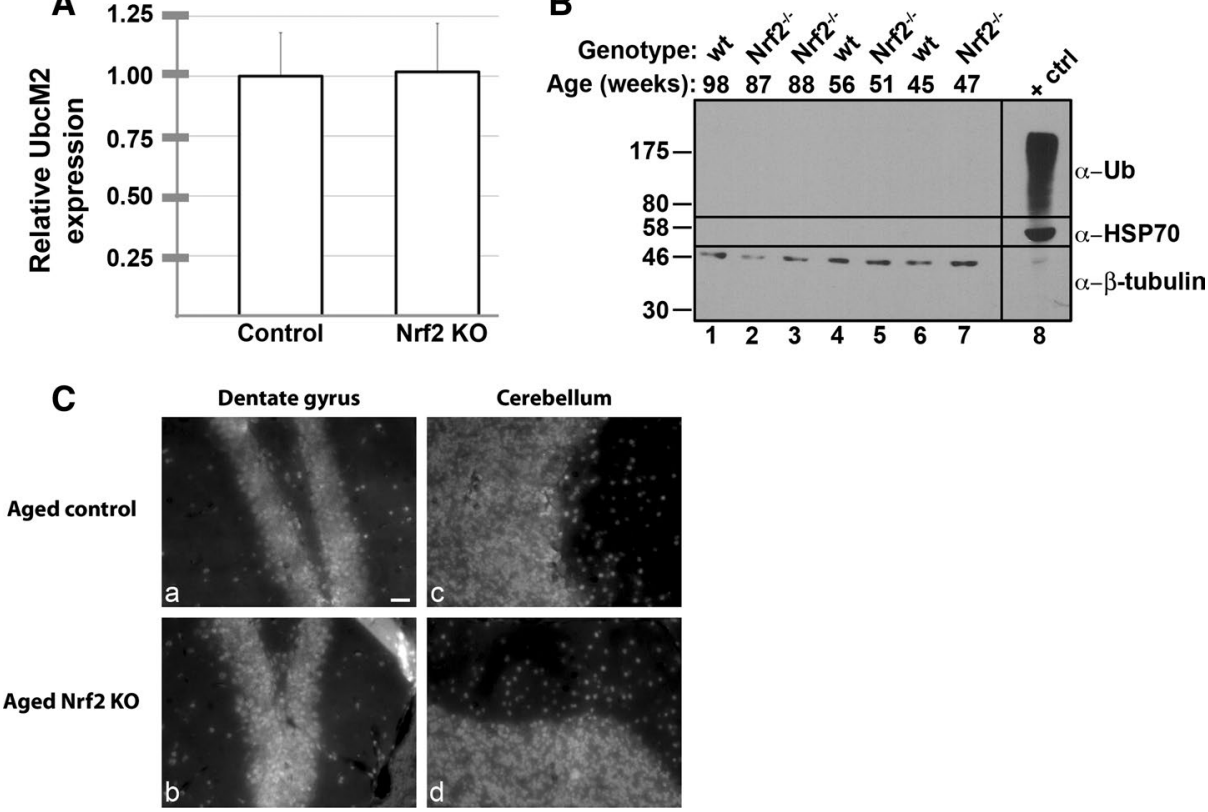

Fig. 5 UbcM2 expression is not altered in Nrf2-deficient brains. A Average expression of UbcM2 in whole brain, consisting of the analysis of 20 substructures, indicating no change in aged, Nrf2-deficient brain relative to aged, strain-matched controls. $n=5$ in triplicate. B Western blot analyses of Nrf2 knockout and age/strain-matched wt mice to detect markers of proteotoxicity and stress. Antibodies used are listed to the right of each panel, and the age and genotype of the mice are indicated above each lane. The positive control (+ctrl) for HSP70 induction and the accumulation of polyubiquitylated proteins is from retinal pigment epithelium (RPE-1) cells treated for $8 \mathrm{~h}$ with $10 \mu \mathrm{m}$ proteasome inhibitor MG132 and harvested with 2 times concentrated Laemmli buffer. The vertical line between lanes 7 and 8 represents a lane in which molecular weight markers were run. The migration of these markers is indicated to the left. $\mathbf{C}$ Representative photomicrographs of dentate gyrus $(a, b)$ and cerebellum $(c, d)$ from aged Nrf2-deficient (92 week; $b, d$ ) and strain-matched control (98 week; $a, c$ ) brains immunolabeled with an a-ubiquitin antibody

reticular formation, pontine nuclei, facial nucleus, and cerebellum. These data fit with the notion that UbcM2 may contribute to motor function and thereby potentially play a role in motor deficits that characterize a number of neurodegenerative diseases. Notably, GWAS data indicate that UbcM2 can interact with ATXN1 [16], a protein linked to spinocerebellar ataxia (SCA). This condition is marked by motor deficits resulting from cerebellar degeneration, dysfunction of both the UPS and the mitochondria, and an accumulation of Ub-positive aggregates [29]. Interestingly, UbcM2 is enriched in the cerebellum and appears to decline with age (Fig. 4A; Table 1). Moreover, UbcM2 has been shown to ubiquitylate TDP-43 [17], a protein involved in amyotrophic lateral sclerosis (ALS). ALS is a motor disease that can result from degeneration of upper motor neurons located in the motor cortex or reticular formation of the brainstem, both of which express relatively high levels of UbcM2 (Fig. 3B; Table 1). These interactions potentially link the enzyme to the neurodegenerative motor disorders of SCA and ALS. UbcM2 could also be linked to non-pathological, age-related motor deficits as the enzyme is abundant in the cortico-ponto-cerebellar tract, an important motor pathway, and decreases in motor cortex and cerebellar granule cells with age. Both of these structures degenerate in normal aging and contribute to age-related motor dysfunction [30].

\section{Conclusions}

In conclusion, we have performed the first protein expression profiling of a Ub-conjugating enzyme in the mouse brain. We show that the class III E2 UbcM2 is ubiquitously expressed in neurons and oligodendrocytes but is not prevalent in microglia or astrocytes. By quantifying relative $\alpha$-UbcM2-derived fluorescence from immunohistochemically stained mouse brain sections, we have determined the relative structure-specific neuronal expression of the enzyme. Further, we have observed a modest decrease in neuronal UbcM2 expression in particular sub-structures of the aged mouse brain.

\section{Methods}

\section{Antibodies}

$\alpha$-UbcM2 was raised in rabbits against a recombinant $\mathrm{His}_{6}$-S-tagged polypeptide corresponding to the unique $\mathrm{N}$-terminal 58 residues of the enzyme 
Table 2 UbcM2 expression does not change in aged Nrf2deficient brains relative to wild type controls

\begin{tabular}{lcc}
\hline Brain structure & $\begin{array}{l}\text { UbcM2 expression \% } \\
\text { change in Nrf2 KO mice }\end{array}$ & P value \\
\hline Amygdala & -1.296 & 0.83 \\
CA1 & -5.181 & 0.53 \\
CA2 & -1.623 & 0.86 \\
CA3 & -4.655 & 0.54 \\
Caudate putamen & 5.078 & 0.61 \\
Cerebellum-granule & -2.908 & 0.66 \\
Dentate gyrus & -2.956 & 0.72 \\
Globus pallidus & 6.630 & 0.37 \\
Inferior colliculus & -5.409 & 0.77 \\
Motor ctx-primary & 4.739 & 0.42 \\
Nu accumbens & 1.304 & 0.89 \\
Orbital ctx & 8.293 & 0.19 \\
Piriform ctx & 5.063 & 0.40 \\
Sensory ctx-primary & -3.221 & 0.61 \\
Spinal trigeminal nu & 9.589 & 0.12 \\
Substantia nigra & 1.952 & 0.71 \\
Superior colliculus & 9.722 & 0.27 \\
Thalamus-lateral & -8.556 & 0.24 \\
Thalamus-ventral & -2.289 & 0.77 \\
Visual ctx-secondary & 7.426 & 0.26 \\
\hline
\end{tabular}

(MSSDRQRSDDESPSTSSGSSDADQRDPAAPEPEEQ EERKPSATQQKKNTKLSSKTTAK), as previously described [12]. Commercially-available, validated antibodies used throughout these immunofluorescence studies include: mouse polyclonal $\alpha$-GFAP (1:500; Neuromics
MO22136), mouse monoclonal $\alpha$-myelin CNPase (1:2500; Covance SMI-91R), mouse monoclonal $\alpha$-Iba1 (1:200; EMD Millipore MABN92), mouse monoclonal $\alpha-\mathrm{NeuN}$ (1:2000; EMD Millipore MAB377), mouse monoclonal $\alpha$-ubiquitin (1:500; Santa Cruz sc-8017), and mouse monoclonal $\alpha$-cre recombinase (1:2000; Millipore MAB3120). Secondary antibodies used were Alexa ${ }_{546 \mathrm{~nm}}$ Fluor-conjugated goat $\alpha$-rabbit IgG and Alexa ${ }_{488 \mathrm{~nm}}$ Fluor-conjugated goat $\alpha$-mouse IgG (1:1000, Molecular Probes). Antibodies used for western blotting include mouse monoclonal $\alpha$-HSP70 (1:1000; Enzo, Inc ADI-SPA-810), mouse monoclonal $\alpha$-Ub (1:1000; Santa Cruz sc-8017), and mouse monoclonal anti- $\beta$-tubulin (1:1000; Sigma Aldrich T4026). Details for each are listed in Table 3.

Cell culture, siRNA transfections, and immunofluorescence UbcM2-specific siRNA or control siCON siRNA (Dharmacon, Inc.) were combined with INTERFERin (Polyplus transfection) for $10 \mathrm{~min}$ at room temperature before being added to $35,000 \mathrm{HeLa}$ or hTERT RPE-1 (cat \# CRL-4000; ATCC) cells seeded in 12-well dishes on glass coverslips. A final concentration of $10 \mathrm{nM}$ siRNA was added to the cells in DMEM (cat. \# 10-013$\mathrm{CV}$; Mediatech, Inc.) supplemented with $10 \%$ fetal calf serum (FCS), 100 units $/ \mathrm{mL}$ penicillin, and $0.1 \mathrm{mg} /$ $\mathrm{ml}$ streptomycin sulfate. $72 \mathrm{~h}$ post-transfection, cells were fixed in $3.7 \%$ formaldehyde in PBS for $15 \mathrm{~min}$ at room temperature and permeabilized in $0.2 \%$ Triton X-100 in PBS for 10 min on ice. Cells were then incubated in blocking solution consisting of $3 \%$ bovine serum albumin (BSA) in PBS for $3 \mathrm{~h}$ before being incubated in $\alpha$-UbcM2 diluted at 1:500 in blocking solution

Table 3 Antibodies used in this study

\begin{tabular}{|c|c|c|c|}
\hline Antibody & Immunogen & $\begin{array}{l}\text { Manufacturer, host, mono-/poly-clonal, catalog } \\
\text { number, RRID }\end{array}$ & Conc. used \\
\hline Anti-UbcM2 & $\begin{array}{l}\text { Recombinant } \mathrm{His}_{6} \text {-S-tagged unique N-terminal } \\
\text { extension (MSSDRQRSDDESPSTSSGSSDAD } \\
\text { QRDPAAPEPEEQEERKPSATQQKKNTKLSSKTTAK) }\end{array}$ & In-house, rabbit, polyclonal & $\begin{array}{l}1: 500(\mathrm{IHC}) / \\
1: 1000(\mathrm{WB})\end{array}$ \\
\hline Anti-Cre recombinase & aa 77-343 fusion protein & $\begin{array}{l}\text { EMD Millipore, mouse, monoclonal, MAB3120, } \\
\text { RRID:AB_2085748 }\end{array}$ & $1: 2000$ \\
\hline Anti-GFAP & $\begin{array}{l}\text { Recombinant GFAP, boosts with GFAP purified from } \\
\text { bovine spinal cord }\end{array}$ & $\begin{array}{l}\text { Neuromics, mouse, polyclonal, MO22136, } \\
\text { RRID:AB_2341541 }\end{array}$ & $1: 500$ \\
\hline Anti-myelin CNPase & Purified human myelin CNPase & Covance, mouse, monoclonal, SMI 91, RRID:AB_10120658 & $1: 2500$ \\
\hline Anti-lba1 & Linear peptide corresponding to human Iba1/AIF1 & $\begin{array}{l}\text { EMD Milipore, mouse, monoclonal, MABN92, } \\
\text { RRID:AB_10917271 }\end{array}$ & $1: 200$ \\
\hline Anti-NeuN & Purified cell nuclei from mouse brain & $\begin{array}{l}\text { EMD Millipore, mouse, monoclonal, MAB377, } \\
\text { RRID:AB_2298772 }\end{array}$ & $1: 2000$ \\
\hline Anti-HSP70 & Native human HSP70 & $\begin{array}{l}\text { Enzo, mouse, monoclonal, ADI-SPA-810, } \\
\text { RRID:AB_10616513 }\end{array}$ & $1: 1000$ \\
\hline Anti-ubiquitin & $\begin{array}{l}\text { Amino acids 1-76 representing full length ub of } \\
\text { bovine origin }\end{array}$ & $\begin{array}{l}\text { Santa Cruz Biotechnology, mouse, monoclonal, sc-8017, } \\
\text { RRID:AB_628423 }\end{array}$ & $\begin{array}{r}1: 1000(\mathrm{WB}) / \\
1: 500(\mathrm{IHC})\end{array}$ \\
\hline Anti- $\beta$-tubulin & Tubulin from rat brain & $\begin{array}{l}\text { Sigma-Aldrich, mouse, monoclonal, T4026, } \\
\text { RRID:AB_477577 }\end{array}$ & 1:1000 \\
\hline
\end{tabular}


for $1 \mathrm{~h}$ at room temperature. Cells were subsequently washed in PBS, incubated in secondary antibody plus 4',6-diamidino-2-phenylindole (DAPI; $0.1 \mu \mathrm{g} / \mathrm{mL}$ ) in blocking solution for $1 \mathrm{~h}$, washed again, and mounted on glass slides.

To generate MEFs, pregnant UbcM2 $2^{\text {Flox/Flox }}$ mice were sacrificed 13.5 days post-coitus and embryos removed by manual dissection from amniotic sacs, washed with ethanol, and the limbs, tail, red organs, and head above the eyes were removed. The remaining material was minced with a sterile razor blade in $4.5 \mathrm{~g} / \mathrm{L}$ glucose-containing DMEM containing penicillin and streptomycin and trypsinized for $10 \mathrm{~min}$ at $37^{\circ} \mathrm{C}$. Non-soluble material was removed by centrifugation, and the remaining cells were cultured in $4.5 \mathrm{~g} / \mathrm{L}$ glucose-containing DMEM containing penicillin, streptomycin, and $10 \%$ FCS. MEFs were subsequently transduced with a lentivirus expressing a trimethoprim-inducible Cre recombinase, and Cre expression was induced by adding $10 \mu \mathrm{M}$ trimethoprim to the media for at least $24 \mathrm{~h}$.

\section{Mouse brain tissue preparation}

All animal care was performed in compliance with The Oklahoma Medical Research Foundation Institutional Animal Care and Use Committee-approved protocol. $\mathrm{Nrf2}{ }^{-/-}$mice (10-25 months) were backcrossed 10 generations into a C57BL6 background and have been previously described $[26,31]$. C57BL/6 mice were used in the control (1-4 months) versus aged (10-25 months) analysis. Mice were euthanized by $\mathrm{CO}_{2}$ asphyxiation and decapitated to remove brains. Tissue was fixed in $10 \%$ neutral buffered formalin at $4{ }^{\circ} \mathrm{C}$ overnight then processed and paraffinized using an overnight protocol with ethanol, xylene, and paraffin equilibration in a Shandon Excelsior tissue processor (Thermo Scientific). Brains were cut into $7 \mu \mathrm{m}$-thick sagittal sections using a Leica Instruments Microtome (Model 2045 Multicut), mounted on charged glass slides, and warmed on a LabLine Instruments slide warmer (Model 26020) overnight. A mouse brain atlas [20] was used throughout the sectioning process to ensure correct orientation using white matter, cerebellum, and various structural markers as landmarks. These same landmarks were observed to ensure studies compared the same sagittal plane within each brain, although we observed very similar UbcM2 expression levels in various planes of the same substructures within a brain (data not shown).

\section{Immunohistochemistry}

Slides were deparaffinized by washes in Histo-Clear (National Diagnostics) followed by serial washes in decreasing amounts of ethanol and then water. Heatinduced epitope retrieval was performed using a Retriever
2100 (Electron Microscopy Sciences) in the accompanying R-buffer AG, and slides were allowed to cool in the retriever for 4-20 h. Slides were then washed in PBS and incubated in blocking solution consisting of $10 \%$ goat serum and $3 \%$ BSA in PBS for $1-3 \mathrm{~h}$ at room temperature. Sections were incubated in $\alpha$-UbcM2 (1:500) or $\alpha$-Ubiquitin (1:500) and a cell-type specific antibody in blocking solution at $4{ }^{\circ} \mathrm{C}$ overnight. The following day, the slides were washed in PBS and incubated in secondary antibody and DAPI at $0.1 \mu \mathrm{g} / \mathrm{mL}$ or Hoechst33342 at $1 \mu \mathrm{g} /$ $\mathrm{mL}$ diluted in $3 \% \mathrm{BSA}$ in PBS for $1 \mathrm{~h}$ at room temperature in the dark. After a final PBS wash, slides were mounted using ProLong Gold (Cell Signaling Technology) and examined with a Nikon 80i microscope and DXM1200C camera. Images were captured using NIS-Elements software (Nikon), and representative images were processed in Adobe Photoshop (Version 8.0). Of note, all sections quantitatively compared corresponded to a similar parasagittal plane of the brain, were processed at the same time in parallel with the same diluted reagents, and were imaged using identical gain, exposure, and binning settings.

\section{Western blotting}

Brain lysates were prepared from 5 month-old female C57BL/6 mice that were euthanized by $\mathrm{CO}_{2}$ asphyxiation and decapitated to remove brains for dissection of cerebellum and cortex on a cold block. Structures were lysed in a buffer consisting of $150 \mathrm{mM} \mathrm{NaCl}, 20 \mathrm{mM}$ Tris [pH 8], 1 \% Triton X-100, 2 mM EDTA, and 1 tablet phosphatase inhibitor (Thermoscientific PI 88266), homogenized with a pestle, and incubated on ice 1-2 $\mathrm{h}$ before sonication. Debris was removed by centrifugation, and supernatants collected for analysis. Brain or cell culture lysates were boiled in 2 times concentrated (2X) Laemmli solubilizing buffer (100 mM Tris [pH 6.8], 2 \% SDS, $0.008 \%$ bromophenol blue, $2 \%$ 2-mercaptoethanol, $26.3 \%$ glycerol, and $0.001 \%$ Pyrinin Y), resolved by SDS-PAGE and transferred to nitrocellulose. Blots were blocked in $5 \%$ nonfat milk/TBST $(0.1 \%$ Tween- 20 in Tris-buffered saline) before incubation with primary antibodies. All primary antibodies were diluted 1:1000 in $5 \%$ nonfat milk/TBST. Horseradish peroxidase (HRP)conjugated secondary antibodies were diluted in $5 \%$ Milk/TBST, and blots were processed with enhanced chemiluminescence.

\section{Neuronal UbcM2 expression analysis}

For each genotype or age comparison, 5 animals were used per group as biological replicates, and per animal, 3 sequential sections on 1 slide were analyzed as technical replicates such that a total of 15 brain sections from 5 animals represent each genotype/age group. A separate $20 \times$ picture was taken of each substructure analyzed, and all 
cells (50-150 nuclei) were evaluated in each image. Only nuclear expression was observed and quantitated, as this study and our previous work demonstrate that UbcM2 is exclusively expressed in the nucleus [13]. UbcM2 expression was measured in terms of $\alpha$-UbcM2-derived fluorescent intensity in NeuN-positive nuclei using NIH ImageJ software. Separate grayscale pictures were taken for each of the three channels corresponding to nuclei, NeuN, and UbcM2. In ImageJ, each raw NeuN image was subjected to a user-defined threshold such that only NeuN-positive areas were represented. The fluorescence intensity of each NeuN-positive cell was then measured in the corresponding raw UbcM2 image on a scale of 0-255 pixels. Each nuclear UbcM2 measurement was normalized to the background intensity of that image with background defined as an average value of 10 separate measurements of visually UbcM2-negative areas.

\section{Statistical analysis}

In each of the two comparative studies, namely young vs old and Nrf2 knockout vs wildtype, the enzyme level dependence on the covariates was analyzed by fitting a Linear Mixed Effects Model implemented as the lme function in the nlme $\mathrm{R}$ package. This function is essentially an extended version of the classical linear regression but is able to accommodate complex data collection design features such as nested layers and within-group correlation. The method formulation [32], computational method [33], and implementation of the model in R [34] have previously been described in detail. As described in the previous section, data collection design involved 3 embedded layers for each group (where group refers to old, young, Nrf2 knockout, or Nrf2 strain-matched wildtype control) as 50-150 measurements (cells) per 22 (aged study) or 20 (Nrf2 study) substructures were analyzed in three sequential brain sections per mouse. Accordingly, the data was analyzed by performing an unequal sample sizes multilevel nested lme where protein level dependence on the fixed effects, namely variable (age or genotype), brain structure, and their interactions, was analyzed with the embedded data collection structure designated as a random effect represented as Mouse/Replicate/Structure. Significance of UbcM2 expression changes in whole brain was assessed with the lme version of the ANOVA function applied on the lme object. Fixed effect coefficient significance tables were extracted with the tTable method while confidence intervals were returned by the intervals function in the nlme package (Tables 1,2 ; Figs. 3B, 4B, C, 5A). Slight testing power boosting was achieved by using one-sided tests with the null hypothesis matching the expectation that UbcM2 levels are lower in old mice.

\section{Additional file}

Additional file 1: Figure S1. UbcM2 is ubiquitously expressed in neurons of mouse brain. Representative photomicrographs from a $7 \mu \mathrm{m}$ paraffin-embedded sagittal brain section from a 4-month old C57BL/6 mouse. Nuclei are counterstained with Hoechst (white, panels a, e, i, m), and immunostaining is shown for neuronal nuclear marker NeuN (green, panels $b, f, j, n$ ) and UbcM2 (red, panels $c, g, k, o$ ). Neuronal UbcM2 expression is represented as yellow in the NeuN and UbcM2 merged images (panels d, h, l, p). A) Hippocampus: CA1 (panels a-d), CA2 (panels e-h), CA3 (panels i-l), and dentate gyrus (panels m-p). B) Hindbrain: cerebellum (panels a-d), facial nucleus (panels e-h), lateral reticular formation (panels $i-l)$, pontine nuclei (panels $m-p$ ), and spinal trigeminal nucleus (panels $\mathrm{q}-\mathrm{t}$ ). C) Cortex: cingulate cortex (panels a-d), primary motor cortex (panels e-h), secondary motor cortex (panels i-l), primary sensory cortex (panels $m-p)$, and secondary visual cortex (panels $q-t)$. D) Midbrain: inferior colliculus (panels $a-d$ ), superior colliculus (panels e-h), laterodorsal thalamus (panels $\mathrm{i}-\mathrm{I}$ ), and ventral anterior thalamus (panels $\mathrm{m}-\mathrm{p}$ ). E) Ventrorostral: caudate putamen (panels a-d), lateral hypothalamus (panels e-h), nucleus accumbens (panels i-l), and olfactory nucleus (panels m-p). 20X, size bars $=30 \mu \mathrm{m}$

\section{Abbreviations}

UPS: ubiquitin proteasome system; Ub: ubiquitin; E1: ubiquitin activating enzyme; E2: ubiquitin conjugating enzyme; E3: ubiquitin protein ligase; siCON: siRNA control; siUbcM2: UbcM2-specific siRNA; DAPI: 4',6-diamidino-2-phenylindole; SCA: spinocerebellar ataxia; ALS: amyotrophic lateral sclerosis.

\section{Authors' contributions}

All authors had full access to all of the data in the study and take responsibility for the integrity of the data and the accuracy of the data analysis. Study concept and design: CML and SMP, Acquisition of data: CML, Analysis and interpretation of data: CML and SMP, Drafting of the manuscript: CML and SMP, Critical revision of the manuscript for important intellectual content: CML, CG, JDW, and SMP, Statistical Analysis: CML and CG, Funding: SMP. All authors read and approved the final manuscript.

\section{Author details \\ ${ }^{1}$ Aging and Metabolism Research Program, Oklahoma Medical Research Foundation, 825 Northeast 13th Street, Oklahoma City, OK, USA. ${ }^{2}$ Arthritis and Clinical Immunology Research Program, Oklahoma Medical Research Foundation, 825 Northeast 13th Street, Oklahoma City, OK, USA. ${ }^{3}$ Oklahoma Center for Neuroscience, University of Oklahoma Health Sciences Center, Oklahoma City, OK, USA.}

\section{Acknowledgements}

This work was supported by National Institutes of Health Grant R01 GM092900 (to S.M.P.), Grant HR13-182 from The Oklahoma Center for the Advancement of Science and Technology (to S.M.P.), NIH/NCRR grant 5P20GM103636 (to J.D.W), and a John and Mildred Carson Predoctoral Fellowship (to C.M.L). We thank members of the Plafker laboratory for helpful discussions and Dr. William Sonntag (University of Oklahoma Health Sciences Center) for generously sharing several antibodies. Special thanks to Kendra Plafker for assistance with antibody validation and to Blake Hopiavuori for sharing expertise in brain dissection and lysate preparation.

\section{Competing interests}

The authors declare that they have no competing interests.

Received: 5 March 2015 Accepted: 24 August 2015

Published online: 13 November 2015

\section{References}

1. Ye Y, Rape M. Building ubiquitin chains: E2 enzymes at work. Nat Rev Mol Cell Biol. 2009;10(11):755-64. 
2. Kleiger G, Mayor T. Perilous journey: a tour of the ubiquitin-proteasome system. Trends Cell Biol. 2014;24(6):352-9.

3. Oddo S. The ubiquitin-proteasome system in Alzheimer's disease. J Cell Mol Med. 2008;12(2):363-73.

4. McNaught KS, Olanow CW, Halliwell B, Isacson O, Jenner P. Failure of the ubiquitin-proteasome system in Parkinson's disease. Nat Rev Neurosci. 2001;2(8):589-94.

5. Kinnunen K, Petrovski G, Moe MC, Berta A, Kaarniranta K. Molecular mechanisms of retinal pigment epithelium damage and development of age-related macular degeneration. Acta Ophthalmol. 2012;90(4):299-309.

6. Shang F, Taylor A. Roles for the ubiquitin-proteasome pathway in protein quality control and signaling in the retina: implications in the pathogenesis of age-related macular degeneration. Mol Asp Med. 2012;33(4):446-66.

7. Takalo M, Salminen A, Soininen H, Hiltunen M, Haapasalo A. Protein aggregation and degradation mechanisms in neurodegenerative diseases. Am J Neurodegener Dis. 2013;2(1):1-14.

8. Matuschewski K, Hauser HP, Treier M, Jentsch S. Identification of a novel family of ubiquitin-conjugating enzymes with distinct amino-terminal extensions. J Biol Chem. 1996;271(5):2789-94.

9. Pestov DG, Grzeszkiewicz TM, Lau LF. Isolation of growth suppressors from a cDNA expression library. Oncogene. 1998;17(24):3187-97.

10. Plafker KS, Farjo KM, Wiechmann AF, Plafker SM. The human ubiquitin conjugating enzyme, UBE2E3, is required for proliferation of retinal pigment epithelial cells. Invest Ophthalmol Vis Sci. 2008;49(12):5611-8.

11. Plafker KS, Nguyen L, Barneche M, Mirza S, Crawford D, Plafker SM. The ubiquitin-conjugating enzyme $\mathrm{UbCM} 2$ can regulate the stability and activity of the antioxidant transcription factor Nrf2. J Biol Chem. 2010;285(30):23064-74.

12. Plafker KS, Plafker SM. The ubiquitin-conjugating enzyme UBE2E3 and its import receptor importin-11 regulate the localization and activity of the antioxidant transcription factor NRF2. Mol Biol Cell. 2015;26(2):327-38.

13. Mirza S, Plafker KS, Aston C, Plafker SM. Expression and distribution of the class III ubiquitin-conjugating enzymes in the retina. Mol Vis. 2010;16:2425-37.

14. Suter B, Fontaine JF, Yildirimman R, Rasko T, Schaefer MH, Rasche A, Porras P, Vazquez-Alvarez BM, Russ J, Rau K, et al. Development and application of a DNA microarray-based yeast two-hybrid system. Nucleic Acids Res. 2013;41(3):1496-507.

15. Markson G, Kiel C, Hyde R, Brown S, Charalabous P, Bremm A, Semple J, Woodsmith J, Duley S, Salehi-Ashtiani K, et al. Analysis of the human E2 ubiquitin conjugating enzyme protein interaction network. Genome Res. 2009;19(10):1905-11.

16. Lim J, Hao T, Shaw C, Patel AJ, Szabo G, Rual JF, Fisk CJ, Li N, Smolyar A, Hill DE, et al. A protein-protein interaction network for human inherited ataxias and disorders of Purkinje cell degeneration. Cell. 2006;125(4):801-14.

17. Hans F, Fiesel FC, Strong JC, Jackel S, Rasse TM, Geisler S, Springer W, Schulz JB, Voigt A, Kahle PJ. UBE2E ubiquitin-conjugating enzymes and ubiquitin isopeptidase $Y$ regulate TDP-43 protein ubiquitination. J Biol Chem. 2014;289(27):19164-79.
18. Plafker SM, Macara IG. Importin-11, a nuclear import receptor for the ubiquitin-conjugating enzyme, UbcM2. EMBO J. 2000;19(20):5502-13.

19. Plafker SM, Plafker KS, Weissman AM, Macara IG. Ubiquitin charging of human class III ubiquitin-conjugating enzymes triggers their nuclear import. J Cell Biol. 2004;167(4):649-59.

20. Paxinos G, Franklin KBJ. Paxinos and Franklin's the mouse brain in stereotaxic coordinates. 4th ed. Amsterdam: Elsevier/AP; 2013.

21. Kevei E, Hoppe T. Ubiquitin sets the timer: impacts on aging and longevity. Nat Struct Mol Biol. 2014;21(4):290-2.

22. Vernace VA, Schmidt-Glenewinkel T, Figueiredo-Pereira ME. Aging and regulated protein degradation: who has the UPPer hand? Aging Cell. 2007;6(5):599-606.

23. Hayes JD, Dinkova-Kostova AT. The Nrf2 regulatory network provides an interface between redox and intermediary metabolism. Trends Biochem Sci. 2014;39(4):199-218.

24. Kageyama S, Sou YS, Uemura T, Kametaka S, Saito T, Ishimura R, Kouno T, Bedford L, Mayer RJ, Lee MS, et al. Proteasome dysfunction activates autophagy and the Keap1-Nrf2 pathway. J Biol Chem. 2014;289(36):24944-55.

25. Tsakiri EN, Sykiotis GP, Papassideri IS, Terpos E, Dimopoulos MA, Gorgoulis VG, Bohmann D, Trougakos IP. Proteasome dysfunction in Drosophila signals to an Nrf2-dependent regulatory circuit aiming to restore proteostasis and prevent premature aging. Aging Cell. 2013;12(5):802-13.

26. Zhao Z, Chen Y, Wang J, Sternberg P, Freeman ML, Grossniklaus HE, Cai J. Age-related retinopathy in NRF2-deficient mice. PLoS One. 2011;6(4):e19456.

27. Cahoy JD, Emery B, Kaushal A, Foo LC, Zamanian JL, Christopherson KS, Xing Y, Lubischer JL, Krieg PA, Krupenko SA, et al. A transcriptome database for astrocytes, neurons, and oligodendrocytes: a new resource for understanding brain development and function. J Neurosci. 2008:28(1):264-78.

28. Yanjiang X, Hongjuan H, Tiantian G, Yan Z, Zhijun H, Qiong W. Expression patterns of ubiquitin conjugating enzyme UbcM2 during mouse embryonic development. Gene Expr. 2012;15(4):163-70.

29. Duenas AM, Goold R, Giunti P. Molecular pathogenesis of spinocerebellar ataxias. Brain. 2006;129(Pt 6):1357-70.

30. Luft AR, Skalej M, Schulz JB, Welte D, Kolb R, Burk K, Klockgether T, Voight K. Patterns of age-related shrinkage in cerebellum and brainstem observed in vivo using three-dimensional MRI volumetry. Cereb Cortex. 1999:9(7):712-21.

31. Chan K, Lu R, Chang JC, Kan YW. NRF2, a member of the NFE2 family of transcription factors, is not essential for murine erythropoiesis, growth, and development. Proc Natl Acad Sci USA. 1996;93(24):13943-8.

32. Laird NM, Ware JH. Random-effects models for longitudinal data. Biometrics. 1982;38(4):963-74.

33. Lindstrom ML, Bates DM. Nonlinear mixed effects models for repeated measures data. Biometrics. 1990;46(3):673-87.

34. Pinheiro JC, Bates DM. Mixed effects models in S and S-Plus. New York: Springer; 2000.

\section{Submit your next manuscript to BioMed Central and take full advantage of:}

- Convenient online submission

- Thorough peer review

- No space constraints or color figure charges

- Immediate publication on acceptance

- Inclusion in PubMed, CAS, Scopus and Google Scholar

- Research which is freely available for redistribution

Submit your manuscript at 